\title{
Temporomandibular Joint Magnetic Resonance Imaging Analysis in Adults with Steinert's Myotonic Dystrophy
}

\author{
Análisis con Resonancia Nuclear Magnética de la Articulación Temporomandibular \\ en Pacientes Adultos con Distrofia Miotónica de Steinert
}

Antonio Sergio Guimarães*; Iván Suazo Galdames** \& Suely K. Nagahashi Marie ${ }^{* * *}$

GUIMARÃES, A. S.; SUAZO, G. I. \& MARIE, N. S. K. Temporomandibular joint magnetic resonance imaging analysis in adults with Steinert's myotonic dystrophy. Int. J. Morphol., 31(1):301-306, 2013.

SUMMARY: The aim was to analyze the characteristics of the temporomandibular joint (TMJ) in a group of adult patients suffering from Steinert's muscular dystrophy (DM1). This study included 42 adult patients aged between 21 and 69 years $($ mean = 38.7619; SD = 12.74) who were diagnosed for DM1. Study was conducted using the MRI of right and left TMJ sagittal images taken in maximum intercuspidation position and maximum oral opening without pain, and the following were discussed: a) the quality of the cortical bone in the mandibular fossa, tuberosity, and mandibular head; b) the relationship of mandibular head-disc-joint tuberosity in maximum intercuspidation position; c) the anatomical shape of the articular disc. All patients showed abnormalities in the shape and surface of the cortical bone in the mandibularfossa, tuberosity, and the mandibular head. With regard to the relationship of the mandibular head in the mandibular fossa, $41 \%$ was found in the region $2 \mathrm{~B}, 29 \%$ in $1 \mathrm{~B}, 18 \%$ in $1 \mathrm{~A}, 9 \%$ in $2 \mathrm{C}$, and $3 \%$ in $2 \mathrm{~A}$ of the TMJ. About $49 \%$ of the disc in maximum intercuspidation position was found on the mandibular head, $26 \%$ were anterior displaced, $14 \%$ had anterior dislocations, $38 \%$ had alterations in the form of disc, and 30\% had preserved the anatomical shape. However, $98 \%$ of the discs showed hyposignal in T1 and T2. Using MRI, the decrease in the muscle activity in patients with DM1 was found to generate degenerative changes visible in the TMJ.

KEY WORDS: Temporomandibular joint; Steinert's disease; Myotonic dystrophy; Magnetic resonance imaging.

\section{INTRODUCTION}

Steinert's muscular dystrophy (DM1) is a disease characterized by a progressive decline in the muscle activity (Papageorgiou et al., 2007), owing to the replacement of the muscle fibers by the adipose tissue and an increase in the connective tissue between them, and the major signs of the disease are accompanied by a multisystemic commitment (Schneider et al., 2001). The decrease in the muscle activity is expressed clinically in the so-called myotonic phenomenon, characterized by a slow postisometric muscle relaxation and a decrease in the strength of the bite and hands (Gunkel et al., 2000 and Guimarães et al., 2010).

From the imagenologic point of view, it is possible to observe significant changes in the muscles of mastication in the carriers of diseases that cause fibroadipose degeneration of these muscles (Pomatto et al., 2001), which results in deterioration of the bite strength (Guimarães et al., 2007).
The shape and characteristics of the temporomandibular joint (TMJ) reflect important morphofunctional changes - the presence of dense fibrous tissue covering their joint surface, the stratification and distribution of the cartilage of the mandibular head, the shape, structure, and mechanisms of disc nutrition, etc., are some examples of this adaptation. These features allow the TMJ to respond to the specific functional requirements of the mandibular dynamic with respect to the different functions of the stomatognathic system (Schmolke, 1984). The reduced requirements on TMJ in patients with DM1 can cause adaptive morphological changes; however, there are only a few studies that examined this issue.

Against this background, the objective of this study is to analyze the characteristics of the TMJ in a group of adult carriers of DM1.

\footnotetext{
* Head Institute, Federal University of São Paulo, Paulist School of Medicine, São Paulo, Brazil.

** Facultad de Medicina, Universidad Diego Portales, Santiago, Chile.

** Department of Neurology, School of Medicine, University of São Paulo, Brazil.
} 


\section{MATERIAL AND METHOD}

Sample. The sample of this study included 42 adult patients between 21 and 69 years of age (mean $=38.7619 ; \mathrm{SD}=12.74)$ diagnosed with DM1, previously investigated with the Southern blot method (Southern, 1975) and clinically confirmed.

The patients participated voluntarily, and were informed about the nature of the study and a written record of their consent was obtained. The patients were treated at the Hospital das Clínicas de la Facultad de Medicina de la Universidade de São Paulo (HC-FMUSP). The study was approved by the ethics committee investigation of the HC-FMUSP.

Images Acquired. To obtain the MRI images, the following protocol was carried out for each of the selected patients:

a) Sagittal images of the bilateral TMJ (right and left) in a maximum intercuspidation position.

b) Sagittal images of the bilateral TMJ (right and left) in maximum oral opening without pain.

We used an equipe Phillips, model Gyroscan ACS-II 1.5 Tesla. The sagittal images were obtained on T1-weighted (TR 500 - TE 15) FOV of 145 and T2 (TR 2000 - TE 100) FOV of 140, respectively. The examination lasted for $30 \mathrm{~min}$ for each patient.

Image analysis. The analysis of the nuclear MRI was performed by two expert observers, based on the following criteria:

Quality of the mandibular-fossa cortical, tuberosity, and mandibular head in relation to the parameters of regularity, thickness, shape preserved, presence of erosion, or impossibility to assess.

The positional relationship of the mandibular headmandibular fossa-articular disc in a maximum intercuspidation position: the vertical positioning (supero-inferior position) of the mandibular head in relation to the mandibular fossa was evaluated by drawing a tangential line to the bottom of the mandibular fossa, parallel to the plane of the images obtained, corresponding to the top of the visual field of MRI. Further, another line was drawn parallel to the first, tangential to the tuberosity, and a third at a distance equidistant between the two. Thus, the mandibular fossa was divided into three horizontal compartments, denoted by the letter A for the superior compartment, B for the intermediary compartment, and the letter $\mathrm{C}$ for the lower compartment.
The postero-anterior positioning of the mandibular head was evaluated in relation to the mandibular fossa and the tuberosity, in a maximum intercuspidation position. Vertical lines were drawn perpendicular to the tangential superior line, the first of which goes to the center of the mandibular fossa, another parallel to the center of the corner of the tuberosity, and the third parallel and equidistant from the previous two lines.

This division would split the area between the center of the mandibular fossa and the center of the tuberosity in the vertical compartments, with the number 1 on the first compartment (before the first vertical line), number 2 on the second compartment, number 3 on the third compartment, and so on.

As a result of dividing the region of the mandibular fossa, eight compartments were obtained: $1 \mathrm{~A}$ (supero-posterior), 2A (supero-anterior), 1B (medium-posterior), 2B (medium-central), 3B (medium-anterior), 1C (infero-posterior), $2 \mathrm{C}$ (infero-medial), and 3C (infero-anterior) (Fig. 1).

Evaluation of the anatomical shape of the articular disc was carried out according to the technique given by Helms et al., (1989) and was classified as conserved, altered, or not evaluable. In addition, its resonance signal and its position in relation to the mandibular head, in phases of close mouth in maximum intercuspidation and maximum aperture without pain were recorded. The functional area of the mandibular head to be used was determined by dividing it into two areas. These areas were determined to draw a line in the anteriorposterior region of greater thickness, perpendicular to the longitudinal axis of the mandibular head (MRI sagittal view), from the anterior cortical to the posterior and another orthogonal to the midpoint. The supero-anterior area was considered as the functional area of the mandibular head during the maximum intercuspidation position (Fig. 2).

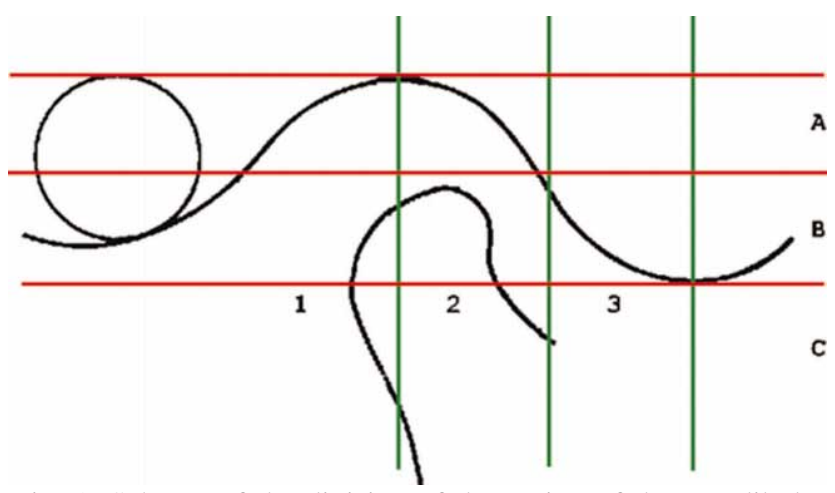

Fig. 1. Scheme of the division of the region of the mandibular fossa for evaluating the positional relationship of the mandibular head/mandibular fossa in the maximum intercuspidation phase. 


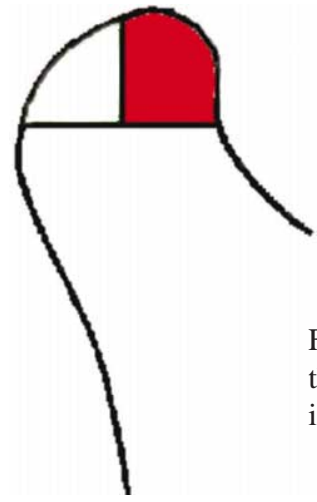

Fig. 2. Scheme with the functional area of the mandibular head during the maximum intercuspidation position.

\section{RESULTS}

\section{Quality of cortical}

a) Cortical of the mandibular fossa. With regard to the condition of the cortical of the mandibular fossa, $54(64 \%)$ had irregular images, $12(14 \%)$ were thick, $9(11 \%)$ were conserved, in $8(10 \%)$ it was not possible to assess the cortical, and 1 was eroded.

b) Cortical of the joint tuberosity. With respect to the status of the cortical in the joint tuberosity, 41 (49\%) had irregular images, $22(26 \%)$ were thick and irregular, $8(10 \%)$ were irregular with erosions, $5(6 \%)$ were thick and eroded, $4(5 \%)$ were thick, irregular, and eroded, $2(2 \%)$ were thick, $1(1 \%)$ was eroded, and $1(1 \%)$ was not available (Fig. 3).

c) Cortical of the mandibular head. With regard to the status of the mandibular-head cortical, 19 (23\%) had irregular images and were flattened, 18 (21\%) were irregular, 14 $(17 \%)$ were irregular and eroded, $6(7 \%)$ were flattened and thickened, 5 (6\%) were flattened, irregular, and eroded, 4 $(5 \%)$ were flattened and eroded, $4(5 \%)$ were conserved, 3 (4\%) were thick, $3(4 \%)$ were thick and eroded, $2(2 \%)$ were irregular and thickened, $2(2 \%)$ were flattened, $2(2 \%)$ were flattened, thick, and eroded, 1 (1\%) was only eroded, and 1 case (1\%) could not be assessed (Figs 4, 5, and 6).

\footnotetext{
Assessing the relationship of the mandibular head and mandibular fossa in maximum intercuspidation position. About 34 (41\%) joints of the mandibular head was found in compartment 2B, 24 (29\%) joints showed mandibular heads displaced to the posterior compartment (1B) in relation to the mandibular fossa, 15 cases $(18 \%)$ were displaced to the posterior and superior compartment (1A), 7 (9\%) occupied superior positions in compartment $2 \mathrm{~A}$, and 2 cases $(3 \%)$ were positioned inferior or occupied the compartment $2 \mathrm{C}$.
}

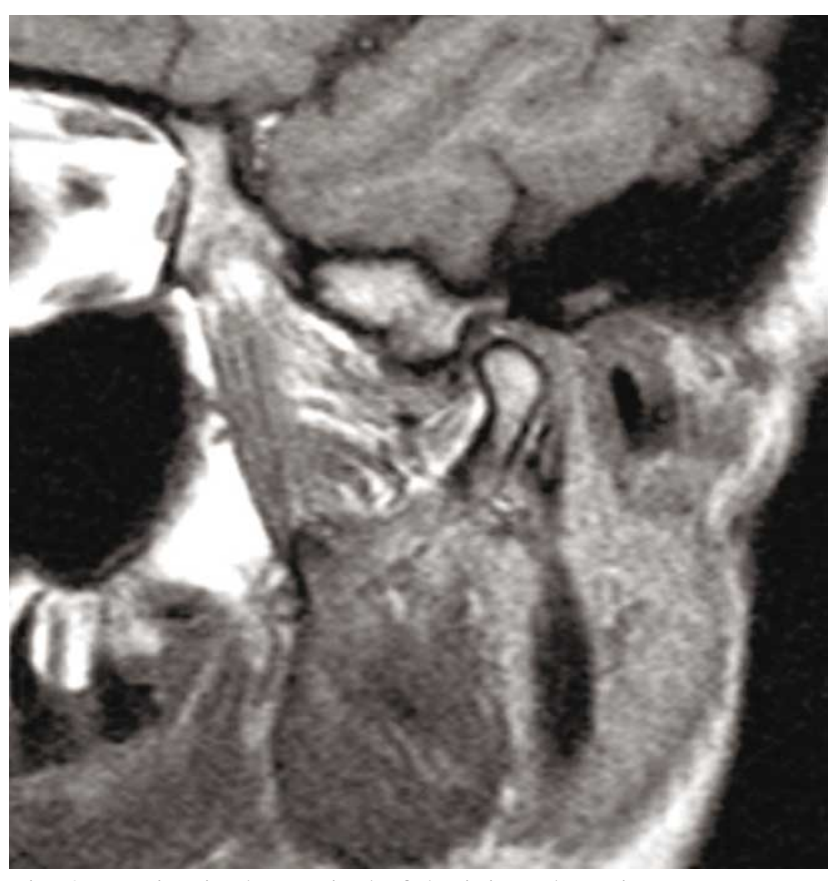

Fig. 3. Erosion in the cortical of the joint tuberosity.

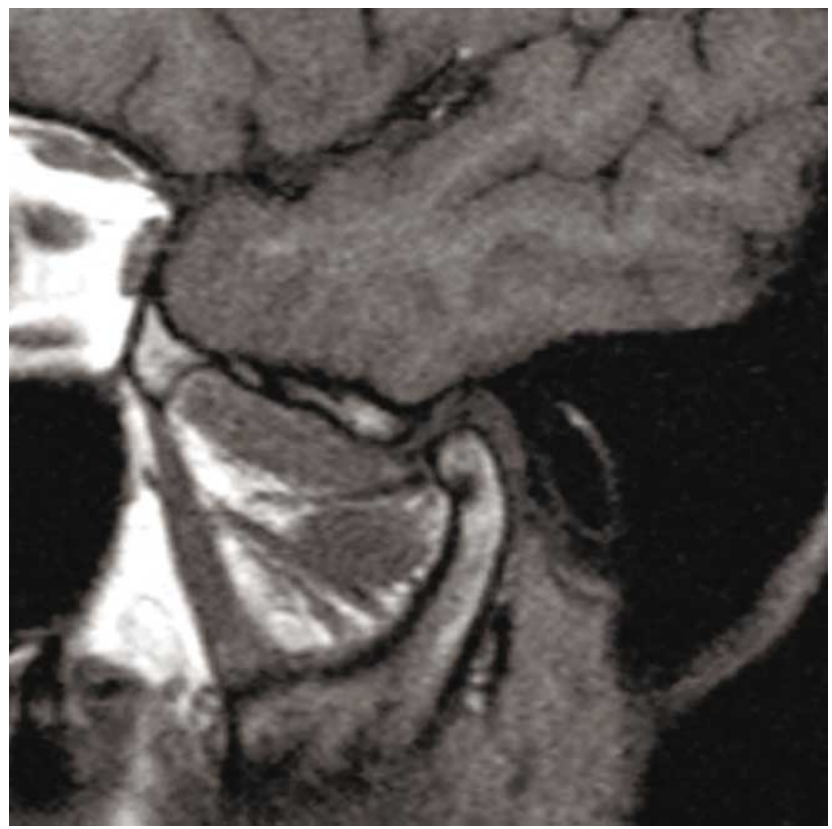

Fig. 4. Erosion at the mandibular head.

\section{Articular disc}

a) Positioning of joint disc in maximum intercuspidation position. In relation to the position of the articular disc with mouth closed in maximum intercuspidation position, 41 $(49 \%)$ of the discs analyzed were over the mandibular head, $22(26 \%)$ with anterior displaced, $12(14 \%)$ with anterior dislocations, and in 9 cases $(11 \%)$, it was not possible to conduct the evaluation. 


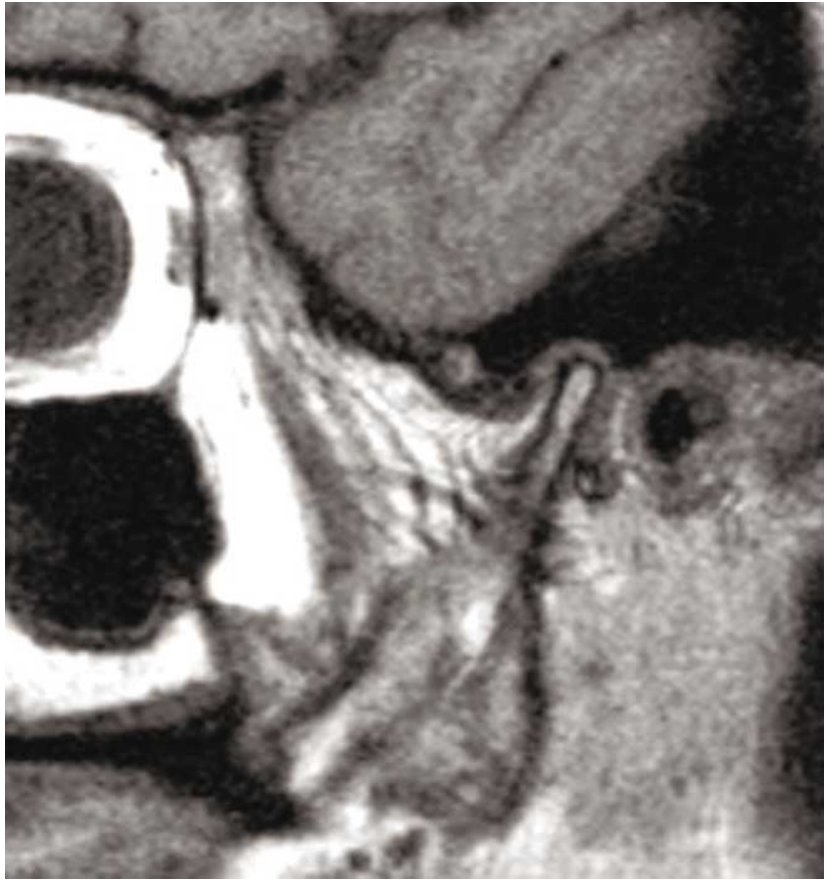

Fig. 5. Alteration of the shape of the mandibular head and anterior dislocation of the disc.

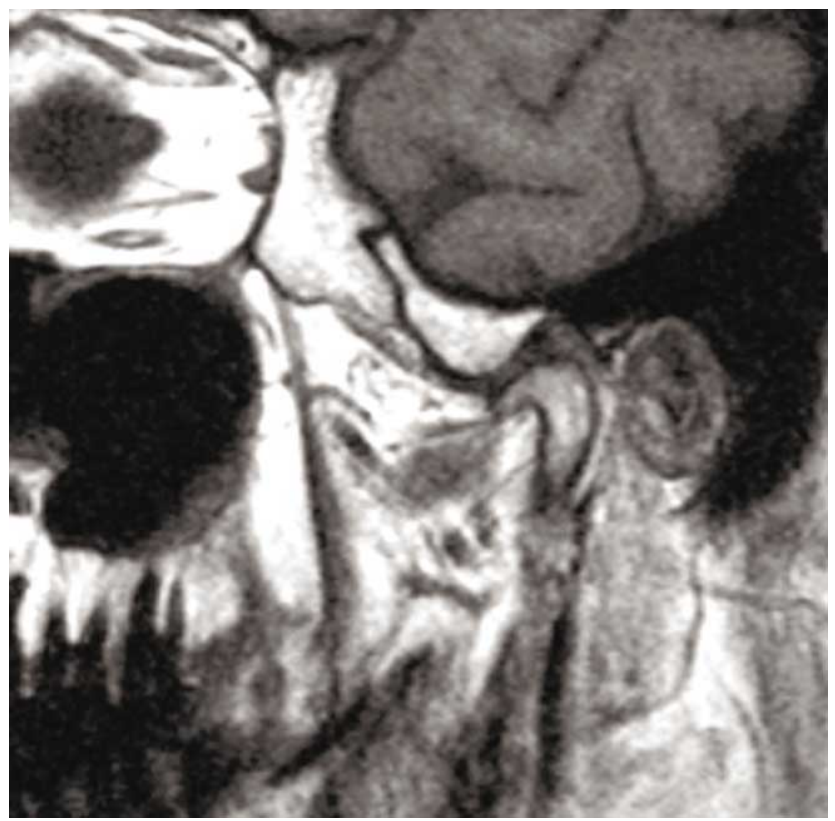

Fig. 6. Flattening of the mandibular-head cortical.

b) Anatomical shape of the articular disc in maximum intercuspidation position. In relation to the shape of the articular disc at the stage of mouth closed in maximum intercuspidation position, 32 (38\%) articular discs had shape alterations, in 27 cases (32\%) it was not possible to perform the analysis, and $25(30 \%)$ had preserved the anatomical shape. c) Signal of joint disc in MRI - Maximum intercuspidation position. About 82 (98\%) of the articular disc had change in the signal (hyposignal in T1 and T2) and in 2 cases (2\%) it was not possible to conduct the analysis.

d) Positioning of joint disc at maximum aperture without pain. At the stage when $76(90 \%)$ of the discs were studied, the central portion of the articular disc was found at the superior apex of the mandibular head, in $5(6 \%)$ cases it was not possible to conduct the evaluation, and 3 cases (4\%) were found anteriorly positioned.

\section{DISCUSSION}

In TMJ, under normal conditions, mandibular head and joint tuberosity relate actively through joint disc, owing to the significant neuromuscular control showing the muscles of mastication. When this activity is altered, the TMJ causes adaptive morphological changes. A clear example is illustrated when the muscle activity increases, and consequently, the joint surface responds by reorganizing the bone and cartilaginous tissue of the joint surface, and generates an adaptation of the disc. If the forces exceed this threshold adaptive, degenerative processes occur in the articulation (Itoh \& Hayashi, 2000). However, not only increased activity can cause major changes in the TMJ, but there are systemic conditions that also cause it, and this study analyzed the morphological characteristics of TMJ in adult patients suffering from DM1 with clinical expression characterized by hypofunction of the muscles of mastication and myotonic phenomenon. In these patients, we observed a high incidence of irregular joint surface (64\% in the mandibular fossa, $49 \%$ in the tuberosity, and $23 \%$ in the mandibular head) that suggests the presence of degenerative processes associated with lower activity than that found under the joint as a result of muscle weakness presented by these patients. This finding is consistent with what was reported earlier by various authors who suggested prolonged periods of hypomobility or burdens of low-rise degenerative changes in the joint surface of the TMJ (Glineburg et al., 1982; Nitzan \& Dolwick, 1989 and Lydiatt \& Davis, 1989). Adaptive changes associated with the articular hypofunction owing to the decrease in the strength of the bite can trigger the reorganization of the fiber of the joint, capsule and ligaments, and the joints propioceptors, allowing the patient to have greater ranges of oral openness, active and passive, which joins the decrease in the muscletendinous propioceptors, owing to the metaplasia of the muscle for fat tissue, contributing to mandibular instability and a greater tendency for dislocation of the articulation (Wilson et al., 1989). The results suggest that the changes also affect the articular disc, which are rather in its structure, 
preserving its relationship with the joint surface. The proper relationship at the maximum aperture without pain in patients analyzed implies that the disc is attached to the mandibular head by an anterior posting, which has been described by various authors as an activity of the superior head of the lateral pterygoid muscle (Ogutcen-Toller \& Juniper, 1993; Zhang et al., 1998 and Bakke et al., 2005). This also affects the muscle in the DM1; however, this does not seem to alter the anterior movements of the disc in harmonious relationship with the mandibular head in the mandibular movements, suggesting that conservation of the form is necessary to keep this relationship (Rao et al., 1990), and this should be taken into account during the surgical procedures that could alter this relationship (Manzon \& Philbert, 2007).

In conclusion, this study demonstrated that the decrease in the muscle activity in patients with DM1 generates changes in TMJ visible with MRI.

GUIMARÃES, A. S.; SUAZO, G. I. \& MARIE, N. S. K. Análisis con resonancia nuclear magnética de la articulación témporomandibular en pacientes adultos con distrofia miotónica de Steinert. Int. J. Morphol., 31(1):301-306, 2013.

RESUMEN: El objetivo de este estudio, fue analizar las características de la articulación temporomandibular (ATM) en un grupo de pacientes adultos portadores de distrofia muscular de Steinert (DM1). Fueron evaluados 42 pacientes adultos, con edades entre 21 y 69 años (Media=38,7619; DE=12,74) diagnosticados con DM1. Se realizó un estudio por RNM de ATM mediante imágenes sagitales de ATM derecha e izquierda en posición de máxima intercuspidación (MIC) y apertura máxima sin dolor, y se analizaron a) la calidad de las corticales de la fosa mandibular, tuberosidad y cabeza mandibular, b) la relación cabeza mandibular- disco- tuberosidad articular en MIC, c) la forma anatómica del disco articular. Todos los pacientes presentaron alteraciones en la forma y superficie de las corticales de la fosa mandibular, tuberosidad articular y cabeza mandibular. Con respecto a la relación de la CM en la FM, el $41 \%$ se encontró en la región 2B, el 29\% 1B, 18\% 1A, 9\% 2A y 3\% 2C de la ATM. El 49\% de los discos en MIC se encontraron sobre la cabeza mandibular, 26\% estaban desplazados anteriormente, 14\% presentaron un dislocamiento anterior. El 38\% presentó alteraciones de la forma del disco y $30 \%$ presentaron conservada la forma anatómica. El 98\% de los discos presentaron hiposeñal en T1 y T2. La disminución de la actividad muscular en los pacientes con DMS genera cambios degenerativos en la ATM visibles con RNM.

PALABRAS CLAVE: Articulación temporomandibular; Enfermedad de Steinert; Distrofia miotónica; Resonancia nuclear magnética.

\section{REFERENCES}

Bakke, M.; Moller, E.; Werdelin, L. M.; Dalager, T.; Kitai, N. \& Kreiborg, S. Treatment of severe temporomandibular joint clicking with botulinum toxin in the lateral pterygoid muscle in two cases of anterior disc displacement. Oral Surg. Oral Med. Oral Pathol. Oral Radiol. Endod., 100:693-700, 2005.

Glineburg, R. W.; Laskin, D. M. \& Blaustein, D. I. The effects of immobilization on the primate temporomandibular joint: a histologic and histochemical study. J. Oral Maxillofac. Surg., 40:3-8, 1982.

Guimarães, A. S.; Carlsson, G. E. \& Marie, S. K. Bite force and handgrip force in patients with molecular diagnosis of myotonic dystrophy. J. Oral Rehabil., 34:195-200, 2007.

Guimarães, A. S; Suazo, G. I. C; Marie N. S. K. Fenómeno miotónico orofacial en pacientes con distrofia miotónica de Steiner. Av. Odontostomatol, 26(3):139-1;42, 2010.

Gunkel, O.; Reichenbach, H.; Thamm, B.; Wetzel, U.; Bratanow, S.; Kirchhof, M.; Lauer, B.; Froster, U. \& Schuler, G. Late diagnosis of Curschmann-Steinert myotonic dystrophy in a female patient with dilated cardiomyopathy and in her son. $Z$. Kardiol., 89:599-605, 2000.
Helms, C. A.; Kaban, L. B. \& McNeil, C. Temporomandibular joint: Morphology and signal intensity characteristics of the disk at MR imaging. Radiology, 172:817-20, 1989.

Itoh, K. I. \& Hayashi, T. Functions of masseter and temporalis muscles in the control of temporomandibular joint loading--a static analysis using a two-dimensional rigid-body spring model. Front. Med. Biol. Eng., 10:17-31, 2000.

Lydiatt, D. D. \& Davis, L. F. The effects of immobilization on the rabbit temporomandibular joint. J. Oral Maxillofac. Surg., 43:188-93, 1989.

Manzon, S. \& Philbert, R. Orthognathic surgery in a patient with myotonic dystrophy: review of literature and report of a case. J. Oral Maxillofac. Surg., 65:2575-9, 2007.

Nitzan, D. W. \& Dolwick, M. F. Temporomandibular joint fibrous ankylosis following orthognathic surgery: report of eight cases. Int. J. Adult Orthodon. Orthognath. Surg., 4:7-11, 1989.

Ogutcen-Toller, M. \& Juniper, R P. The embryologic development of the human lateral pterygoid muscle and its relationships with the temporomandibular joint disc and Meckel's cartilage. J. Oral Maxillofac. Surg., 51:772-778, 1993. 
GUIMARÃES, A. S.; SUAZO, G. I. \& MARIE, N. S. K. Temporomandibular joint magnetic resonance imaging analysis i adults with Steinert's myotonic dystrophy. Int. J. Morphol., 31(1):301-306, 2013.

Papageorgiou, E.; Bock, S. W. \& Schiefer, U. Myotonic dystrophy Curschmann-Steinert. Klin. Monatsbl. Augenheilkd, 224:70$5,2007$.

Pomatto, E.; Castellano, S. \& Bianchi, S. D. Unilateral fibroadipose degeneration of the masticatory muscles. Dentomaxillofac. Radiol., 30:346-8, 2001.

Rao, V. M.; Babaria, A.; Manoharan, A.; Mandel, S.; Gottehrer, N.; Wank, H. \& Grosse, S. Altered condylar morphology associated with disc displacement in TMJ dysfunction: observations by MRI. Magn. Reson. Imaging, 8:231-5, 1990.

Schmolke, C. The relationship between the temporomandibular joint capsule, articular disc and jaw muscles. J. Anat., 184:335$45,1984$.

Schneider, C.; Reiners, K. \& Toyka, K. V. Myotonic dystrophy (DM/Curschmann-Steinert disease) and proximal myotonic myopathy (PROMM/Ricker syndrome). Myotonic muscle diseases with multisystemic manifestations. Nervenarzt, 72:618-24, 2001.

Southern, E. M. Detection of specific sequences among DNA fragments separated by gel electrophoresis. J. Mol. Biol., 98:503-17, 1975.

Wilson, A.; Mackay, L. \& Ord, R. A. Recurrent dislocation of the mandible in a patient with myotonic dystrophy. J. Oral Maxillofac. Surg., 47:1329-32, 1989.

Zhang, L.; Sun, L. \& Ma, X. A macroscopic and microscopic study of the relationship between the superior lateral pterygoid muscle and the disc of the temporomandibular joint. Zhonghua Kou Qiang Yi Xue Za Zhi, 33:267-9, 1998.
Correspondence To:

Prof. Dr. Iván Suazo Galdames

Departamento de Morfofunción

Facultad de Medicina

Universidad Diego Portales

Santiago

CHILE

Email: ivan.suazo@udp.cl

Received: 26-03-2012

Accepted: 18-11-2012 